\title{
Self-Medication Among Adults in Urban Udupi Taluk, Southern India
}

\author{
Mishra Divya, Shetty Bharatesh, Guddattu Vasudeva, Chandrasekaran Varalakshmi
}

\section{Mishra Divya, Shetty Bharatesh, Guddattu Vasudeva, Chandrasekaran Varalakshmi}

Department of Public Health, Manipal University, MANIPAL, Karnataka, INDIA

\section{Correspondence}

Varalakshmi Chandra Sekaran, Dept. of Community Medicine, MMMC, Manipal University, MANIPAL.

Phone number: 0820 - 2922520. Email: drvaralakshmic@gmail.com

History

- Submission Date: 03-09-15.

- Review completed: 18-06-16;

- Accepted Date: 22-06-16.

DOI : 10.5530/ijmedph.2016.3.6

Article Available online

http://www.ijmedph.org/v6/i3

Copyright

(C) 2016 Phcog.Net. This is an open-access article distributed under the terms of the Creative Commons Attribution 4.0 International license.

\begin{abstract}
Background: Practice of self-medication with over-the-counter (OTC) medicines is considered as responsible self-medication and is a topic of growing interest among researchers and health policy makers.
\end{abstract}

Aim: The study aims to find the overall prevalence and factors associated with self-medication among adults in the urban area of Udupi taluk.

Settings and Design: Community based cross-sectional study design in the urban area of Udupi taluk.

Methods and Materials: In a community-based cross- sectional study, data was collected from 290 adults selected from each ward of urban area of Udupi taluk using single stage cluster sampling technique with proportional allocation method. An interview schedule was used for the collection of data. The data was analyzed using SPSS, version 15 (Chicago, IL).

Results: The overall prevalence of self-medication use including allopathic, traditional, homeopathic medicines and home remedies in urban area of Udupi was found to be $35.9 \%$. $195 \%$ $\mathrm{Cl}$ : 30-41). The various socio-demographic factors like age group, marital status, education and occupation as well as socio-economic status were found statistically associated with selfmedication $(\mathrm{p}<0.05)$. Health-related characteristics like presence of health professional in the family, knowledge of OTC medicines and its responsible use were also found to be statistically significant $(p<0.05)$. Accessibility of medicines from the pharmacy without prescription $(p=0.007)$, obtaining quick relief $p=0.034$ and avoiding crowds while visiting doctors $p=0.041$ were found to be statistically significant reasons for self-medication.

Conclusion: Prevalence of self-medication in the urban area of Udupi taluk was comparable to other studies conducted in India. Self-medication as a practice is emerging as an important public health subject; however, the onus is on providing much needed health education and partnership with pharmacists to empower individuals to make informed decisions.

Key words: Over-the-counter, Self-medication, Non-prescription, Prevalence, Medicines.

\section{INTRODUCTION}

Non-prescription medicines are also known as over-the-counter medicines (OTC), which are safe drugs and can be sold over-the-counter without prescription. ${ }^{1}$ Self-medication with OTC medicines is referred as 'responsible' self-medication, but using a prescription medicine without a doctor's supervision is an 'irresponsible' form of self-medication. It is also a form of self-care and is a focus of interest among researchers and health policy makers regarding the advantages and disadvantages associated with its outlooks, self-medication is being considered an important component of primary health care. ${ }^{2,4,5}$ Globally,about half of all medicines are reported to be inappropriately prescribed, dispensed and/ or sold, and non-adherence to physician advice is highly prevalent. ${ }^{6}$ Community-based studies in developing regions such as Asia, Latin America, and Africa, show that almost $80 \%$ of illness was practice in general population. ${ }^{3}$ Even having negative self-treated. ${ }^{7}$ Prevalence of self-medication in developing countries is in the range of $12.7 \%$ to $95 \%$.,

Estimated prevalence of self-medication in India was found to be $31 \%^{4}$ with variable prevalence reported in other studies. ${ }^{2}$ However, there is a lot of concern regarding the irrational use of drugs in self-medication in India. ${ }^{8}$ Easy availability of a wide a major factor responsible for irrational use of drugs resulting in health problems such as antimicrobial resistance, adverse drug events and economic loss. ${ }^{9}$

This study attempted to find the prevalence of selfmedication with both, OTC and prescription only medicines (POM) among adults in urban Udupi taluk and to gain insight into associated factors.

\section{METHOD}

A community-based cross-sectional study was conducted in urban area of Udupi taluk taking households as a sampling unit. Udupi district consists of three range of medicines without prescription in India is

Cite this article : Divya M, Bharatesh S, Vasudeva G, Varalakshmi C. Self-Medication Among Adults in Urban Udupi

Taluk, Southern India. J. Med. Public Health, 2016; 6(3):126-9. 
Table 1: Association between socio-demographic characteristics and self-medication

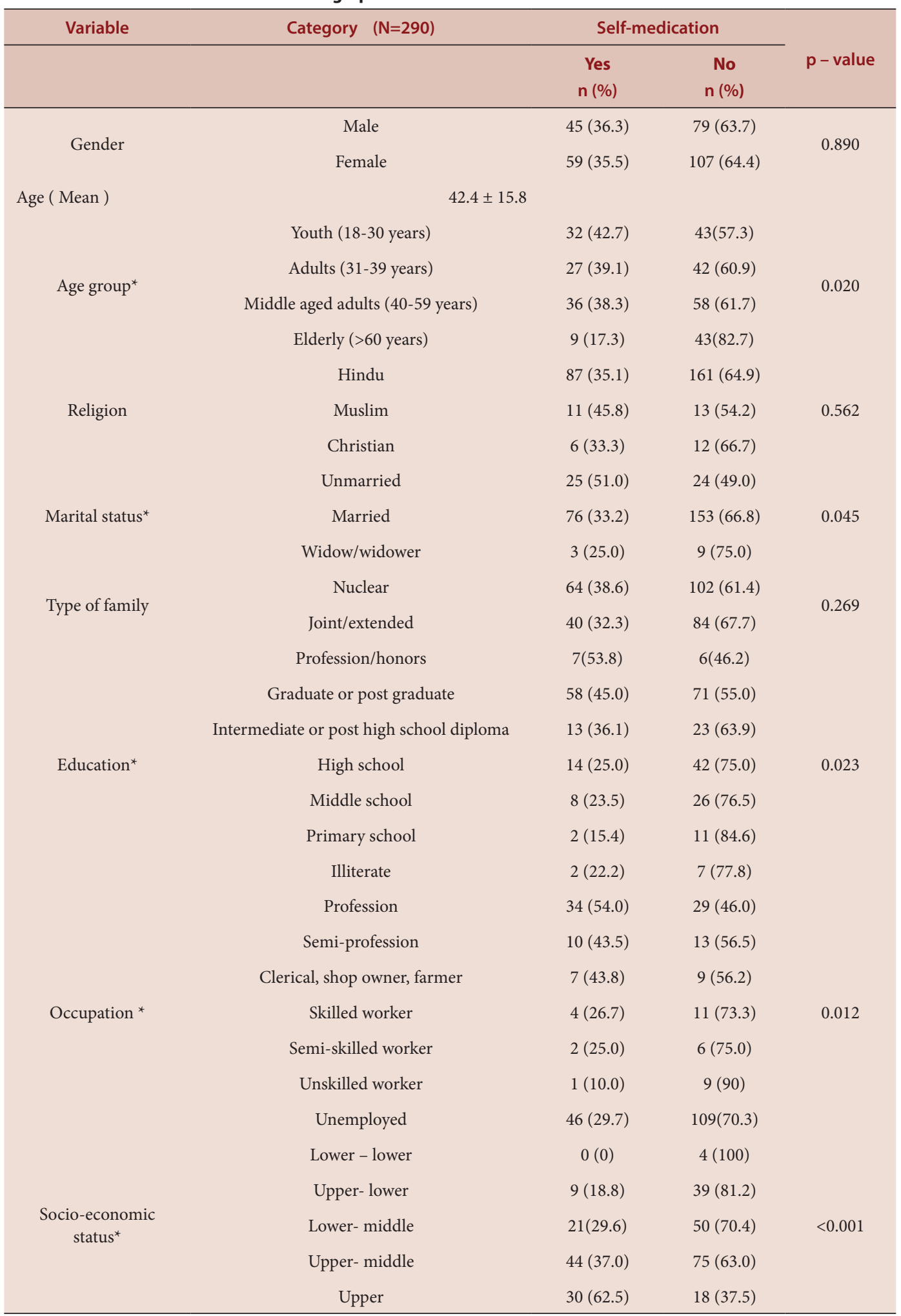

${ }^{*}$ p-value $<0.05$ (Significant). 


\begin{tabular}{|c|c|c|c|}
\hline Reasons stated & $\begin{array}{c}\text { Category } \\
(n=104)\end{array}$ & Self-medication & $\mathrm{p}$-value \\
\hline \multirow{2}{*}{ Minor illness can be treated at home. ${ }^{*}$} & Yes & $77(47.0)$ & \multirow{2}{*}{$<0.001$} \\
\hline & No & $27(21.4)$ & \\
\hline \multirow{2}{*}{ Similarity with the past illness * } & Yes & $65(41.9)$ & \multirow{2}{*}{0.021} \\
\hline & No & $39(28.9)$ & \\
\hline \multirow{2}{*}{ Self-medication is easy and convenient way } & Yes & $44(42.7)$ & \multirow{2}{*}{0.071} \\
\hline & No & $60(32.1)$ & \\
\hline \multirow{2}{*}{ To get a quick relief from illness * } & Yes & $61(41.8)$ & \multirow{2}{*}{0.034} \\
\hline & No & $43(29.9)$ & \\
\hline \multirow{2}{*}{ Due to lack of time } & Yes & $13(48.1)$ & \multirow{2}{*}{0.162} \\
\hline & No & $91(34.60$ & \\
\hline \multirow{2}{*}{ Economical } & Yes & $11(39.3)$ & \multirow{2}{*}{0.691} \\
\hline & No & $93(35.5)$ & \\
\hline \multirow{2}{*}{ To avoid crowd in visiting doctor ${ }^{*}$} & Yes & $18(51.4)$ & \multirow{2}{*}{0.041} \\
\hline & No & $86(33.7)$ & \\
\hline \multirow{2}{*}{$\begin{array}{l}\text { Unavailability of doctor when respondent } \\
\text { visits }\end{array}$} & Yes & $1(14.3)$ & \multirow[t]{2}{*}{0.428} \\
\hline & No & $103(36.4)$ & \\
\hline \multirow{2}{*}{$\begin{array}{l}\text { Unavailability of good health clinics nearby } \\
\text { respondents' residence. }{ }^{* *}\end{array}$} & Yes & $1(100)$ & \multirow[t]{2}{*}{0.359} \\
\hline & No & $103(35.6)$ & \\
\hline
\end{tabular}

${ }^{*}$ p-value $<0.05$ (Significant)

${ }^{* *}$ Fisher's Exact test.

Table 3: Types of medicines stored

\begin{tabular}{cccc}
\hline Variable & Category & $\begin{array}{c}\text { Frequency } \\
(\mathbf{n = 2 3 8 )}\end{array}$ & $\begin{array}{c}\text { Percent } \\
(\%)\end{array}$ \\
\hline & Only OTC & 82 & 34.4 \\
Categories of medicines stored $^{*}$ & Only POM (prescribed) & 40 & 16.8 \\
& POM (prescribed) + OTC & 31 & 13.1 \\
& POM (not-prescribed) + OTC & 71 & 29.8 \\
& POM (prescribed) +POM (non-prescribed)+ OTC & 14 & 5.9 \\
\hline
\end{tabular}

${ }^{*}$ Approved drug list (updated March 2011) ${ }^{31}$ MFDA/2010/PRL/003.

taluks, Udupi, Kundapura and Karkala. Udupitaluk is divided into rural and urban area of Udupi. The urban area of Udupi has City Municipal Council (CMC). According to census 2011, Udupi city has a total 35 wards. These wards were considered as geographically defined clusters. Single stage cluster sampling technique was used for selection of study units. One individual was considered per household. The houses were selected from each cluster by using proportional allocation method. The required sample size adjusted for cluster was 290 households which was equivalent to 290 individuals. Prevalence of self-medication in developing countries varies from the range of $12.7 \%$ to $95 \%$. Varied prevalence rates have been reported in Indian settings. Hence, keeping the variability in mind, a pilot study was conducted in randomly selected wards of Udupi taluk, and the final sample size was selected by using the prevalence estimated in pilot study. The final sample size was estimated based on the following factors: proportion of the event in the population $(\mathrm{P})=66.7 \%$ (from pilot study), $\mathrm{d}=$ Margin of error (0.05), confidence interval $(\mathrm{CI})=95 \%, \varepsilon=$ Relative precision $(10 \%$ of $\mathrm{p})$, design effect $=1.5$. The data was analyzed using Statistical Package for Social Sciences, version 15 (SPSS, Chicago, IL). Descriptive statistics were used to describe socio-demographic characteristics, socio-economic status, patterns of self-medication and prevalence of self-medication. Chi-square test was applied to find out the association of self-medication with sociodemographic, socio-economic and health related characteristics. Also the association between different reasons to self-medicate was obtained. Using 95\% CI, p-value $<0.05$ was considered as significant.

\section{RESULT}

The overall prevalence of self-medication use including allopathic, traditional, homeopathic medicines and home remedies in urban area of Udupi was found to be $35.9 \%$. (95\% CI: 30-41). The factors such as age, marital status, education, occupation and socio-economic status were found to be significantly associated with self-medication $(n=290$, $\mathrm{p}$-value $<0.05$ ). Religion and type of family were not found to be associated with self-medication. The practice of self-medication was found to be high $(42.7 \%)$ in age group 18-30 years and among unmarried individuals (51\%). Self-medication was found to be practiced more frequently among those with higher levels of education which included professionals (53.8\%) followed by graduate or post graduates (45\%). Self-medication was also highly practised by those in professional occupations (54\%). Self-medication was found to be significantly associated with education 
and occupation. The majority of the participants who self-medicated $(62.5 \%)$ belonged to the upper socio-economic class followed by uppermiddle class (37\%). Socio-economic status of the participants was found to be highly significant with the practice of self-medication (Table 1).

Of the 290 respondents, $13 \%$ were found to have at least one health professional in their family. Majority of the participants (77.9\%) reported that their perceived health was satisfactory and stated that they preferred private health facilities (94.8\%) for receiving healthcare than government health facilities. The reasons stated by the participants for preferring private health facilities were that they found them to be more trustworthy, easily accessible and availability of doctors. They also found that they were convenient, provided quick services and they had the option of choosing their own doctor. Many private health facilities had health insurance coverage for the participants as well.

Of the total, half of the participants (50\%) stated that other members in their family also practiced self-medication. Almost half of them, (49.3\%) stated that they sometimes suggested others to take the same medication which was effective for them. Among 238 respondents who reported storage of medicine at home, $42 \%$ had self-medicated. The factors like practice of self-medication among other family members, suggesting others to self-medicate, having heard of OTC medicines and responsible self-medication and keeping stock of medicines at home were found to be significantly associated ( $p$-value $<0.05$ ).

Out of 164 participants who stated that minor illnesses can be treated at home, $47 \%$ practiced self-medication which was also statistically significant $(\mathrm{p}<0.05)$. More than half of the participants who practiced self-medication reported having similarity with past illnesses (53.4\%). Of them, $77.4 \%$ of the participants were aware of the treatment given in the past for the same symptoms followed by $22.6 \%$ who used previous prescription to buy medicines. Obtaining quick relief and avoiding crowds while visiting doctors were also found to be the significant reasons for self-medication with $\mathrm{p}$-value $=0.034$ and 0.041 respectively. These findings were comparable with other studies. ${ }^{10,14}$ (Table 2).

Out of 290 participants, 238 (82.1\%) reported storing medicines at home for self-medication. Majority of the participants stored medicines at home for minor illnesses, emergency purposes and also for chronic ailments. Out of 238 participants, $34.4 \%$ were found to be storing only OTC medicines while $13.1 \%$ were found storing OTC medicines along with prescription medicines recommended by the doctor. In all, $47.5 \%$ of the 238 participants practiced responsible self-medication followed by $29.8 \%$ storing OTC as well as POM without prescription (Table 3).

\section{DISCUSSION}

This present community based study was carried out in urban area of Udupi taluk to find the prevalence of self-medication as well as to assess the factors associated with it. The participants were selected by doing the proportional allocation from each ward of CMC. The study identifies point prevalence of $35.9 \%$ of self-medication (95\% CI: 30, 41). A wide range of self-medication practices between $15 \%$ to $80 \%$ have been reported in earlier studies ${ }^{8,10,11}$ which may be contributed by differences in educational status, socio-economic status, non-availability of health facilities and easy availability of medicines. Gupta P, et al. ${ }^{3}$ in 2011 in Malwani, an urban slum in India, reported that $43.5 \%$ of individuals who practiced self-medication were in the age group of 18-35 years, were unmarried, educated (74.4\%) and were mostly skilled labourers (75.9\%). Similarly, studies conducted in Nigeria and in Pakistan showed significant associations between education and self-medication..$^{12,13}$
In this study, practice of self-medication among other family members, suggestions offered to self-medicate, having knowledge of OTC medicines, responsible self-medication and keeping stock of medicines at home were factors that were found to be significantly associated with the practice of self-medication ( $\mathrm{p}$-value $<0.05$ ). This reveals that the practice of self-medication is influential among community members. Other associated factors included accessibility of medicines from the pharmacy without prescription, suffering from minor ailments, similarity with past illnesses, tendency to obtain quick relief and avoiding crowds while visiting the physician with consequent long waiting hours were found to be associated with the self-medication in this study.

\section{CONCLUSION}

Self-medication as a practice is emerging as an important public health subject. Responsible self-medication may be key in reducing patient burden at the physician's clinic, especially in a resource poor setting like India; however, the onus is on providing much needed health education and partnership with pharmacists to empower individuals to make informed decisions.

\section{ACKNOWLEDGEMENT}

I am greatly indebted to Dr. Ramachandra Bairy (DHO, Udupi) for giving permission to conduct the study and all government authorities for providing relevant data of Udupi taluk.

\section{REFERENCES}

1. Gupta VK, Gupta CD, Patel JR. Assessment of Awareness and Attitudes towards Over-the-Counter (OTC) Drugs amongst Urban Population: A Questionnaire Based Study. Research Journal of Pharmaceutical, Biological and Chemical. 2012;3(2):1037.

2. World self-medication industry: Responsible self-care and self-medication. A world-wide review of consumer's survey. [Internet] Ferney-Voltaire, France Available online at http://www.abimip.org.br/uploads/material de_apoio/ 1296056417_792.pdf.

3. Gupta P, Bobhate P, Shrivastava SR. Determinants of Self Medication practices in an urban slum community. Asian J Pharm Clin Res. 2011;4(3):54-7.

4. Wijaysinghe PR, Jayakody RL, Seneviratne RA. Prevalence and predictors of self-medication in a selected urban and rural district of Sri Lanka. WHO SouthEast Asia Journal of Public Health. 2012;1(1):28-41.

5. A Resource from the American College of Preventive Medicine. Over-the-counter medications: Use in general and special populations, therapeutic errors, misuse, storage and disposal. (US);2011.

6. World Health Organization, Medicines: Rational use of medicines. [Internet] World Health Organization 2010 [cited on 2012 Nov 21]. Available from: http:// www.who.int/mediacentre/factsheets/fs338/en/index.html.

7. Public education in rational drug use: a global survey, Geneva:1997.

8. Balamurugan E, Ganesh K .Prevalence and pattern of self-medication use in coastal regions of South India. British $\mathrm{J}$ of Medical Practitioners. 2011;4(3):a428

9. Sharma R, Verma U, Sharma C.L, Kapoor B. Self-medication among urban population of Jammu city. Indian J Pharmacol. 2005;37(1):40-42.http://dx.doi. org/10.4103/0253-7613.13856.

10. Deshpande SG, Tiwari R. Self-medication-A growing concern. Indian J Med Sci. 1997:51: 93-6.

11. Hussain A, Khanum A. Self-medication among university students of Islamabad Pakistan- a preliminary study. Southern Med Review. 2008;1(1):14-6.

12. Afolabi AO. Factors influencing the pattern of self-medication in an adult Nigerian Population. Annals of African Medicine. 2008;(7)3:120-7.http://dx.doi. org/10.4103/1596-3519.55666.

13. Phalke VD, Phalke DB, Durgawale PM. Self-medication practices in rura Maharashtra. Indian J Communinty Med. 2006;31:34.http://dx.doi. org/10.4103/0970-0218.54933.

14. Malvi R, Bigoniya P, Jain S. A study on self-medication among the people of Bhopal region Madhya Pradesh, India. International Research J of Pharm. $2011 ; 2(12) 163-5$. 